\title{
Main Factors Influencing Winter Visibility at the Xinjin Flight College of the Civil Aviation Flight University of China
}

\author{
Jing Zhang $\mathbb{D},{ }^{1}$ Pengguo Zhao $\left(\mathbb{D},{ }^{2}\right.$ Xiuting Wang, ${ }^{2}$ Jie Zhang, ${ }^{3}$ Jia Liu, ${ }^{4}$ Bolan Li, ${ }^{5}$ \\ Yunjun Zhou, ${ }^{2}$ and Hao Wang ${ }^{6}{ }^{6}$ \\ ${ }^{1}$ Xinjin Flight College, Civil Aviation Flight University of China, Chengdu 611430, China \\ ${ }^{2}$ Plateau Atmosphere and Environment Key Laboratory of Sichuan Province, College of Atmospheric Science, \\ Chengdu University of Information Technology, Chengdu 610225, China \\ ${ }^{3}$ Key Laboratory of Meteorological Disaster of Ministry of Education, Nanjing University of Information Science and Technology, \\ Nanjing 210044, China \\ ${ }^{4}$ Climate Center of Sichuan Province, Chengdu 610072, China \\ ${ }^{5}$ Sichuan Ecological Environment Monitoring Center, Chengdu 610041, China \\ ${ }^{6}$ College of Atmospheric Sounding, Chengdu University of Information Technology, Chengdu 610225, China
}

Correspondence should be addressed to Pengguo Zhao; zpg@cuit.edu.cn

Received 22 May 2020; Revised 22 September 2020; Accepted 5 October 2020; Published 20 October 2020

Academic Editor: Ilan Levy

Copyright (c) 2020 Jing Zhang et al. This is an open access article distributed under the Creative Commons Attribution License, which permits unrestricted use, distribution, and reproduction in any medium, provided the original work is properly cited.

Utilizing routine hourly meteorological data of Xinjin Airport and daily average $\mathrm{PM}_{2.5}$ concentration data for Chengdu, winter visibility characteristics at Xinjin Airport between 2013 and 2017 and their relationship with meteorological conditions and particulate matter were analyzed. Between 2013 and 2017, the average winter visibility in Xinjin Airport was lowest in January, followed by that in December. The occurrence frequency of haze days in winter was much higher than that of nonhaze (clean) days, being $90.2 \%$ and $9.8 \%$, respectively. These were mainly mild haze days, with an occurrence frequency of $44.4 \%$, while severe haze days occurred the least, with a frequency of $7.7 \%$. The linear and nonlinear relationships between winter visibility, meteorological factors, and $\mathrm{PM}_{2.5}$ were measured using daily data in winter from 2013 to 2016. The linear correlation between $\mathrm{PM}_{2.5}$ concentration and visibility was the most evident, followed by that of relative humidity. Visibility had a higher nonlinear correlation with $\mathrm{PM}_{2.5}$ concentration, relative humidity, and dew point depression. When relative humidity was between $70 \%$ and $80 \%$, the negative correlation between visibility and $\mathrm{PM}_{2.5}$ concentration was the most significant and could be described by a power function. The multivariate linear regression equation of $\mathrm{PM}_{2.5}$ concentration and relative humidity could account for $65.9 \%$ of the variation in winter visibility, and the multivariate nonlinear regression equation of $\mathrm{PM}_{2.5}$ concentration, relative humidity, and wind speed could account for $68.1 \%$ of the variation in winter visibility. These two equations reasonably represented the variation in winter visibility in 2017.

\section{Introduction}

With the rapid development of industry and transportation in China, the emission of human-induced air pollutants has intensified. Haze is a type of weather phenomenon, in which many dusts, smoke, or salt particles are suspended in the atmosphere. These particles make the air turbid and can reduce the horizontal visibility to below $10 \mathrm{~km}$. Haze weather has become a considerable area of concern [1]. Low visibility caused by haze is an important meteorological element that directly affects not only the health and life quality of people, especially in developing countries, but also rail, road, maritime, and air traffic safety [2-4].

The characteristics and influencing factors of visibility have attracted worldwide attention, and many studies have been made to discuss the trend of visibility at local, regional, continental, and global scales [4-10]. Wang et al. [10] studied the change of clear sky visibility over land, globally, between 1973 and 2007, revealing that, since the mid-1980s, developed regions such as Europe and North America 
displayed a general increasing trend in visibility, while a substantial decreasing trend was observed in South and East Asia, South America, Australia, and Africa. In the megacities of Chicago, Los Angeles, and New York, visibility gradually improved, reaching a very high level from 1973 to 2015 [11]. Conversely, from 1974 to 2018, a significant loss of visibility was observed in East African [12]. In India, during the period of 1961-2008, visibility decreased [11, 13]. Over southwest Germany, a distinct decrease in visibility was measured, from 45 to $25 \mathrm{~km}$ [14]. Since the 1950s, the visibility in the United Kingdom has improved [15], with major improvements observed after the 1973 oil crisis [5]. In Central Europe, the generally low visibility was a consequence of emissions from human activities [16].

Many studies have been carried out on the trends in visibility and its influencing factors in China, primarily focusing on rapidly developing megacities and polluted areas, such as Beijing, Shanghai, Guangzhou, Southeast China, the Yangtze River Delta, and the Pearl Delta region [17-27]. Visibility in the 31 provincial capital cities in China declined markedly between 1973 and 1986, plateaued between 1987 and 2006, and increased slightly after 2007 [28]. The long-term trend in visibility change indicated a progressive degradation in air quality in Baoji from 1980 to 2012 [29]. Located in southwest China, the Sichuan Basin is one of the most populous regions in China and is recognized as a significant haze region, with visibility less than $10 \mathrm{~km}$ since the 1970s [30].

Atmospheric visibility is a complex issue, caused by the scattering and absorption of light by particles and gases. It is affected by the concentration, size, and composition of particulate matter (PM) and meteorological factors [31]. Many studies have shown the connections between atmospheric composition and visibility [32-38]. Visibility is particularly influenced by $\mathrm{PM}_{2.5}$ (particles with an aerodynamic diameter $<2.5 \mu \mathrm{m}$ ) [39]. $\mathrm{PM}_{2.5}$ contributed $34.2 \%$ of the light extinction coefficient, followed by $\left(\mathrm{NH}_{4}\right)_{2} \mathrm{SO}_{4}(30.0 \%)$ [29]. The major components of $\mathrm{PM}_{2.5}$, including sulfate $\left(\mathrm{SO}_{4}\right)$ and elemental carbon, ammonium $\left(\mathrm{NH}_{4}\right)$, nitrate $\left(\mathrm{NO}_{3}\right)$, and soils (crustal minerals), are the main factors contributing to light absorption and scattering [40]. Most aerosols are hygroscopic, and aerosol particles absorb water, leading to increased size and increased light scattering, which lead to reduced visibility [41].

The relationship between meteorological parameters (e.g., relative humidity $(\mathrm{RH})$, temperature, wind speed, and wind direction) and visibility is linearly (nonlinearly) correlated [42-45]. These parameters influence the sources and sinks of trace gases and aerosol particles in the atmosphere and affect visibility. Higher temperatures can influence the production of secondary organic aerosol particles. Wind can lead to a cleaning effect by replacing polluted air with cleaner air, and high wind speed can resuspend dust particles and generate sea spray aerosol particles. $\mathrm{RH}$ is strongly negatively correlated with visibility, and it affects the hygroscopic growth of particles to increase the scattering efficiency, which can directly reduce visibility and influence the size and composition of aerosol particles [46].
Considering the influences of air pollutants and meteorological factors on visibility simultaneously, in Chengdu, the largest city in southwest China, high $\mathrm{RH}$ and a large ammonium sulfate loading were the main factors causing visibility degradation when visibility was lower than $1.5 \mathrm{~km}$ [40]. Chen et al. [30] demonstrated that high RH and the low wind speed increased the occurrence of low visibility events under high $\mathrm{PM}_{10}$ concentrations in Chengdu and Chongqing. Wen et al. [43] indicated that air pollutant concentrations significantly influence visibility and that wind speed is an important meteorological parameter that affects atmospheric turbidity through the diffusing of air pollutants. Lin et al. [20] focused on the effects of meteorological conditions and suspended particles on visibility in Beijing; due to the high $\mathrm{RH}$, summer had the lowest mean visibility; during the 2008 Olympics, the blue-sky hour rate increased significantly when the mean $\mathrm{PM}_{10}$ index (in the form of the ambient air pollution index) reduced to 53, and $\mathrm{RH}$ (aerosol) contributed 24\% (76\%) of the improvement in visibility.

Fireworks and bonfires have been shown to have significant short-term impacts on visibility [47-49]. They are used during religious and cultural festivals, as well as in large sporting and other events. They raise pollutant concentrations (such as $\mathrm{PM}_{2.5}, \mathrm{PM}_{10}$, and $\mathrm{NO}_{\mathrm{x}}$ ) during and immediately after the firework or bonfire event, resulting in a short-term impact on visibility. Secondary inorganic species are dominant fractions of $\mathrm{PM}_{2.5}$ [47], and wet aerosols cause greater light scattering than dry aerosols.

The impact factors affecting atmospheric visibility vary between different regions, with the influence of $\mathrm{RH}$, wind speed, and $\mathrm{PM}_{2.5}$ being the most prominent. In this study, the factors influencing visibility at Xinjin Airport were analyzed. Xinjin Airport is affiliated with the Xinjin Flight College of the Civil Aviation Flight University of China (CAFUC). The Xinjin Flight College of CAFUC was founded in 1957 and is located in Xinjin County, Chengdu, Sichuan Province, in southwest China. Xinjin Flight College has a well-trained instructor team and reliable maintenance staff and mainly focuses on flight training in primary teaching aircraft, medium teaching aircraft, and the helicopter. Surrounded by mountains and rivers, the airport is prone to low visibility events due to high $\mathrm{RH}$, especially in winter. Due to the distinct topography and meteorological background of the Sichuan Basin, it is necessary to study the factors influencing visibility and establish a forecast model, which can then be used to provide an acceptable reasonable reference for flight training.

\section{Materials and Methods}

As shown in Figure 1, Xinjin Airport (code ZUXJ) is located in the west of the Sichuan Basin. The automatic observation station is $300 \mathrm{~m}$ from the boundary of the runway and $120 \mathrm{~m}$ from the centerline of the runway.

According to the standards of the Civil Aviation Administration of China for meteorological ground observations, the dominant visibility is the maximum distance visible to an observer within a $180^{\circ}$ arc within the field of 




Figure 1: The geographical location of Sichuan Province and Xinjin Airport.

view from an observation platform and is measured by using reference features, such as buildings, lights, and mountains, located in different directions. At Xinjin Airport, a forward scatter visibility meter (Vaisala Corporation, Finland) accurately reflects the meteorological optical range (MOR) in the direction of the runway, which is based on the measurement of the atmospheric extinction coefficient or atmospheric light attenuation coefficient. At Xinjin Airport, the artificial observation platform is situated on the roof of a building, approximately $10 \mathrm{~m}$ high, located near the runway. In this study, hourly observations were conducted by an observer, who stood on the observation platform and looked towards the surrounding reference features. They recorded the visibility in all directions, calculated the dominant visibility, regarding the MOR value of the forward scatter visibility meter, made adjustments within a certain range, and then determined the dominant visibility.

Hourly data for a range of meteorological factors, including temperature, air pressure, $\mathrm{RH}$, wind (wind direction and wind speed), and clouds (cloud type, cloud cover, and cloud height), were collected and processed using an automatic weather observation system, developed by Beijing Metled Information Technology Co. Ltd (METLED), located in the automatic observation station at Xinjin Airport. The observation period was from 8:00 am to 8:00 pm, equating a total of 13 hourly data points. The hourly meteorological data and manual visibility data were representative, accurate, and comparative and contribute to information exchange between the national civil aviation and meteorological departments.

Air quality data were collected from eight national air quality monitoring (AQM) sites in Chengdu, for the period from January 1, 2013, to December 31, 2017, and the location of Chengdu is labeled in Figure 1. The mean air pollutant concentrations of Chengdu were calculated by averaging the mass concentrations at all national AQM sites [50]. Daily average concentrations were published following quality assurance and control procedures of the Sichuan Ecological Environment Monitoring Centre, based on the Technical Guideline on Environmental Monitoring Quality Management HJ 630-2011 (http://kjs.mep.gov.cn) [51]. The daily average concentration of $\mathrm{PM}_{2.5}$ was recorded in $\mu \mathrm{g} / \mathrm{m}^{3}$. According to the common seasonal division basis of meteorology, winter is defined from December to February of the following year.

The daily mean meteorological data were calculated by averaging the 13 hourly data points. To investigate trends in visibility and the influence of atmospheric aerosol particles and meteorology on visibility, the daily mean mass concentration of $\mathrm{PM}_{2.5}$ and the daily mean meteorological data were analyzed.

Obstruction to vision, caused by precipitation, sandstorms, blowing sand, floating dust, smoke, blowing snow, snowstorms, high humidity ( $\mathrm{RH} \geqq 90 \%)$, and other weather phenomena, was eliminated by using a weather phenomenon code during data processing to remove the influence of meteorological factors [22]. The maximum visibility in this study is $10000 \mathrm{~m}$; according to the civil aviation meteorological observation standard, the visibility is greater than or equal to $10000 \mathrm{~m}$, and the value is recorded as 10000 . According to meteorological standard [52], haze is classified into four levels based on visibility (VIS): slight haze $(5000 \mathrm{~m} \leqq \mathrm{VIS}<10000 \mathrm{~m})$, mild haze $(3000 \mathrm{~m} \leqq \mathrm{VIS}<5000 \mathrm{~m}), \quad$ moderate haze $\quad(2000$ $\mathrm{m} \leqq \mathrm{VIS}<3000 \mathrm{~m}$ ), and severe haze (VIS $<2000 \mathrm{~m}$ ). The day with the visibility greater than or equal to $10000 \mathrm{~m}$ is defined as a nonhaze (clean) day.

In this study, the characteristics of the winter visibility at Xinjin Airport between 2013 and 2017 were explored through a comprehensive analysis of meteorological and 
environmental factors comprehensively using correlation analysis. Multivariate linear and nonlinear regression equations were established based on the analysis of the linear and nonlinear correlation between each factor and visibility for the period of 2013-2016. The accuracy of these established equations was tested using 2017 data, and then some theoretical guidance for the prediction of the winter visibility in Xinjin Airport was provided finally.

\section{Factors Influencing Visibility}

3.1. Characteristics of Visibility at Xinjin Airport. The average winter visibility at Xinjin Airport between 2013 and 2017 was $5778.8 \mathrm{~m}$. The average visibility in December $(5412.1 \mathrm{~m})$ and January $(4976.6 \mathrm{~m})$ was lower than the mean value. The average visibility in February was $7008.2 \mathrm{~m}$, which was significantly higher than the average winter visibility.

Figure 2(a) shows that the occurrence frequency of severe haze did not change substantially in the winter during the period of 2013-2017. The highest frequency was $11 \%$ in 2016 , followed by $9 \%$ in 2015 , while the frequencies in other years were similar to each other. The occurrence frequency of moderate haze showed a decreasing trend, with an anomaly of $33 \%$ observed in 2016 . The minimum frequency of moderate haze was only $2 \%$ in 2017 . The frequency of mild haze showed an increasing trend with a peak frequency of $33 \%$ in 2017 and a minimum of 19\% in 2015. The frequency of slight haze was increasing year by year and was the largest of the four levels, exceeding $30 \%$ in each year. The maximum frequency of a slight haze was $61 \%$ in 2015, and the minimum was $32 \%$ in 2016 . A distance of $5000 \mathrm{~m}$ is an important critical value of visibility due to the particular characteristics of the flight training subject at Xinjin Airport. The occurrence frequency of haze days decreased slightly when the visibility was less than $5000 \mathrm{~m}$, and the maximum frequency was $68 \%$ in 2016 , followed by $60 \%$ in 2013 . The minimum frequency was $39 \%$ in 2015 . The decreasing frequency of haze days corresponded to an increase in visibility, allowing flight training on more days. As shown in Figure 2(b), the average monthly winter visibility during the period of 2013-2017 showed a generally increasing trend. Corresponding to Figure 2(a), the average visibility was $4361.2 \mathrm{~m}$ in 2016 and $4746.4 \mathrm{~m}$ in 2013, and both values were less than the average annual value $(5778.8 \mathrm{~m})$. A series of measures have been taken to promote environmental protection in Sichuan Province in recent years. Air pollutant emissions significantly decreased following the large-scale shutdown of the unqualified factories. Thus, particulate matter concentrations reduced, and overall visibility increased obviously in 2017.

Table 1 shows the number and frequency of different levels of pollution days at Xinjin Airport in winter during the period of 2013-2017, as well as the corresponding average visibility, $\mathrm{RH}$, and $\mathrm{PM}_{2.5}$ concentration. There were 303 haze days and 33 nonhaze days in total during the period of 2013-2017. The frequencies of haze days and nonhaze days were $90.2 \%$ and $9.8 \%$ respectively, which showed that the occurrence of haze days was much larger than that of nonhaze days. Slight haze days occurred the most, for a total of 150 days (44.4\%). The number of severe haze days was the lowest, only 26 days (7.7\%). Exacerbated by pollution, average humidity increased from $64.9 \%$ for slight haze to $82.1 \%$ for severe haze, and the corresponding $\mathrm{PM}_{2.5}$ concentration increased significantly from $83.1 \mu \mathrm{g} / \mathrm{m}^{3}$ to $208 \mu \mathrm{g} / \mathrm{m}^{3}$. High $\mathrm{RH}$ promotes the hygroscopic growth of fine particles, increasing the extinction effect of particles and reducing visibility [46]. The average $\mathrm{PM}_{2.5}$ concentrations for nonhaze days, slight haze days, and mild haze days at Xinjin Airport were relatively similar to those in Wuhan, while average concentrations for moderate haze days and severe haze days were 20 and $50 \mu \mathrm{g} / \mathrm{m}^{3}$ higher at Xinjin Airport, respectively, highlighting geographical differences [53].

The wind rose diagram of mean winter visibility (Figure 3(a)) shows that easterly wind (E) and east-southeasterly wind (ESE) occurred the most during severe haze days, with a frequency less than 10 . In moderate haze days, the dominant wind directions were ESE, E, and eastnortheasterly (ENE), with a corresponding frequency of more than 10. The frequency of north-easterly wind (NE), south-southeasterly wind (SSE), westerly wind (W), and southerly wind (S) was relatively low, with each recorded less than 10 times during the study period. In mild haze days, the dominant wind direction was E, with a frequency of more than 30. The wind directions ENE, ESE, and south-easterly (SE) were recorded approximately 20 times, while the $S$ wind was recorded less, on approximately 10 times. In slight haze days, ESE and E winds were recorded the most, on approximately 50 to 60 times, followed by SE, S, and SSE winds. NE wind was recorded more than 20 times, while southsouthwesterly (SSW) and south-westerly (SW) winds were recorded approximately 10 times.

As shown in Figure 3(b), when the wind speed was less than $0.5 \mathrm{~m} / \mathrm{s}$, the prevailing wind directions were ENE, NE, $\mathrm{E}$, and SE, with corresponding times between 10 and 20 . When the wind speed was 0.5 to $1 \mathrm{~m} / \mathrm{s}$, the prevailing wind direction was E, ESE, ENE, and NE, with a corresponding frequency between 30 and 40; S wind direction was recorded less, with a frequency of 10 times. When the speed was 1 to $2 \mathrm{~m} / \mathrm{s}$, ESE wind was most frequent, occurring more than 50 times, followed by SE, S, and SSE winds, which occurred approximately 30 times each. The ENE wind also occurred more than 30 times, while SW and SSW winds were recorded approximately 10 times. When the speed was 2 to $3 \mathrm{~m} / \mathrm{s}, \mathrm{E}$ wind was recorded most frequently, occurring more than 50 times, followed by SE, SSE, and S winds, which each occurred approximately 30-40 times; SW, SSW, and W winds occurred less than 10 times. It was notable that the $S$ wind had the highest wind speeds, averaging 2.8 to $3 \mathrm{~m} / \mathrm{s}$, while $\mathrm{W}$ wind averaged 2.6 to $2.8 \mathrm{~m} / \mathrm{s}$. The wind direction gradually changed from $\mathrm{E}$ to $\mathrm{S}$ as the wind speed increased.

Based on the wind rose diagram of mean visibility and wind speed, strong winds, greater than $2 \mathrm{~m} / \mathrm{s}$, and high visibility occurred most frequently in a SE and $\mathrm{E}$ directions. In these directions, as the wind speed increases, the visibility increases significantly. When the visibility was less than $2000 \mathrm{~m}$ or greater than $5000 \mathrm{~m}$, the prevailing wind directions were both $\mathrm{E}$ and ESE, which indicated that the effect of wind direction on visibility at Xinjin Airport was not 




(a)



Year/month

(b)

Figure 2: Frequency of different intensity levels of haze days (a) and the monthly mean winter visibility (b) between 2013 and 2017 in Xinjin Airport.

TABLE 1: Visibility, relative humidity, and $\mathrm{PM}_{2.5}$ concentration under different levels of haze days in Xinjin Airport in winter from 2013 to 2017.

\begin{tabular}{lccccc}
\hline Pollution level & Number of days $(\mathrm{d})$ & Frequency $(\%)$ & Average visibility $(\mathrm{m})$ & Average humidity $(\%)$ & Average $\mathrm{PM}_{2.5}\left(\mu \mathrm{g} / \mathrm{m}^{3}\right)$ \\
\hline Severe & 26 & 7.7 & 1588.8 & 82.1 & 208.0 \\
Moderate & 48 & 14.2 & 2566.7 & 78.5 & 155.6 \\
Mild & 79 & 23.4 & 3963.1 & 75.2 & 126.6 \\
Slight & 150 & 44.4 & 7649.7 & 64.9 & 83.1 \\
Nonhaze & 33 & 9.8 & 10000.0 & 60.0 & 50.0 \\
\hline
\end{tabular}

obvious. Statistical analysis of wind at Xinjin Airport indicated that the prevailing winds were northerly wind $(\mathrm{N})$ and $\mathrm{S}$ throughout the year. $\mathrm{N}$ winds were usually the result of the cold air moving southward and were generally accompanied by precipitation. The data of obstruction to vision caused by precipitation was eliminated in the preliminary work; therefore, the occurrence frequency of northerly winds was small overall.

\subsection{Analysis of the Factors Influencing the Visibility}

3.2.1. Linear Correlation Analysis. The impacts of meteorological and environmental factors on visibility were analyzed. Figure 4 shows the relationship between daily average temperature, air pressure, $\mathrm{RH}$, dew point depression, wind speed, $\mathrm{PM}_{2.5}$ mass concentration, and daily average visibility at Xinjin Airport in winter between 2013 and 2016.

As shown in Figure 4(a), there was a positive correlation between temperature and visibility; however, the correlation coefficient was 0.036 and was not significant at the $99 \%$ confidence level. The coefficient between air pressure and visibility was 0.147 and was significant at the $99 \%$ confidence level (Figure 4(b)). Figure 4(c) indicates that the visibility decreased as $\mathrm{RH}$ increased; the correlation coefficient was -0.65 and was significant at the $99 \%$ confidence level. Visibility increased as the wind speed increased (Figure 4(d)); the correlation coefficient was 0.28 and was significant at the 99\% confidence level. An increase in wind speed raises upward transmission from the ground, causing air to mix and destroying the static stability of the atmosphere. However, increased wind speed promotes pollutants diffusion; therefore, pollutant concentrations decrease and visibility increases [53]. There was a positive correlation between visibility and dew point depression (Figure 4(e)). The correlation coefficient was 0.615 and was significant at the $99 \%$ confidence level. The correlation coefficient between visibility and $\mathrm{PM}_{2.5}$ mass concentration was 0.668 and was significant at the $99 \%$ confidence level (Figure 4(f)). As the most prominent factor affecting winter visibility, an increase in $\mathrm{PM}_{2.5}$ mass concentration caused significant decrease in visibility.

Overall, winter visibility at Xinjin Airport was most closely relevant to $\mathrm{PM}_{2.5}$ concentration, followed by $\mathrm{RH}$ and dew point depression. The relationship between visibility and air pressure and temperature was relatively weak, which was consistent with that observed in Nanjing [54]. The correlation coefficient between visibility and wind speed was also high, which was consistent with the previous studies 



(a)



Wind speed $\left(\mathrm{ms}^{-1}\right)$



(b)

Figure 3: The wind rose diagrams of mean visibility (a) and wind speed (b).

[27, 43]. At Xinjin Airport, the contribution of thermal factors such as RH was much larger than that of the dynamic factors, such as wind speed, which was consistent with the results of Chen et al. [30], where lower visibility in Chongqing was influenced the most by high RH among all factors investigated.

Figure 5(a) shows the impact of $\mathrm{RH}$ and $\mathrm{PM}_{2.5}$ concentration on visibility. There was a negative linear correlation between visibility and $\mathrm{RH}$ in all kinds of haze days. The linear correlation coefficients were all at the $95 \%$ confidence level, except for moderate haze days. The correlation coefficient for severe haze days was -0.44 , the greatest of all, while the $P$-value was 0.02 , slightly lower than those for the mild and slight haze days, which were 0.008 and less than 0.001 , respectively. The impact of $\mathrm{RH}$ on visibility was complex under high humidity conditions. The impact of RH on visibility changed with different levels of air pollution [24].

As shown in Figure 5(b), there was a negative linear correlation between visibility and $\mathrm{PM}_{2.5}$ concentration in all kinds of haze days. Except for moderate haze days, the linear correlation was all at the $95 \%$ confidence level. For slight and mild haze days, the correlation was at the $99.9 \%$ confidence level, which indicated that the direct impact of $\mathrm{PM}_{2.5}$ concentration on high visibility and low visibility was very significant.

Overall, the linear correlation between $\mathrm{PM}_{2.5}$ concentration and visibility was higher than that of $\mathrm{RH}$ in all kinds of haze days. The correlations between visibility and $\mathrm{RH}$ and $\mathrm{PM}_{2.5}$ mass concentration were relatively lower in moderate haze days.
3.2.2. Nonlinear Correlation Analysis. Previous studies have suggested that there are nonlinear correlations between visibility and $\mathrm{RH}, \mathrm{PM}_{2.5}$ concentration, and wind speed [45]. In Guangzhou, in Southeast China, there was a power function relationship between visibility and aerosol particle concentration [55]. In the central cities of Liaoning Province, in Northeast China, the correlation between visibility and fine aerosol particles was logarithmic [56]. Figure 6 shows the nonlinear correlations between visibility and $\mathrm{PM}_{2.5}$ concentration, $\mathrm{RH}$, dew point depression, and wind speed. As shown in Figure 6(a), the results were consistent with those in Guangzhou [55]. There was a power function with a negative relationship between visibility and $\mathrm{PM}_{2.5}$ concentration at Xinjin Airport, and the explained variance was $46.87 \%$. The correlation between visibility and $\mathrm{RH}$ declined exponentially, and the explained variance was $45.58 \%$ (Figure 6(b)). The correlation between visibility and dew point depression was logarithmic, and the explained variance was $44.46 \%$ (Figure 6(c)). There was a power function with a positive relationship between visibility and wind speed, and the explained variance was $11.78 \%$ (Figure 6(d)).

The correlation between visibility and $\mathrm{PM}_{2.5}$ concentration varied with the changes of RH [53]. Figure 7 shows the nonlinear regression of visibility and $\mathrm{PM}_{2.5}$ concentration under different $\mathrm{RH}$ conditions. At the same $\mathrm{PM}_{2.5}$ concentration, visibility decreased when $\mathrm{RH}$ increased. In high humidity and low $\mathrm{PM}_{2.5}$ concentration, and vice versa, visibility could be the same, which showed the synergistic effect of $\mathrm{PM}_{2.5}$ concentration and $\mathrm{RH}$ on visibility. When the concentration of $\mathrm{PM}_{2.5}$ was less than $100 \mu \mathrm{g} / \mathrm{m}^{3}$, visibility 




(a)



(c)



(e)



(b)



$-y=1497.763 x+3888.900, r=0.28044$

(d)



(f)

FiguRe 4: Relations between visibility and temperature (a), air pressure (b), relative humidity (c), wind speed (d), dew point depression (e), and $\mathrm{PM}_{2.5}$ concentration (f).

increased sharply with a decrease in concentration. However, when the value was greater than $100 \mu \mathrm{g} / \mathrm{m}^{3}$, the change in visibility slowed significantly. Therefore, when the concentration of $\mathrm{PM}_{2.5}$ was lower than $100 \mu \mathrm{g} / \mathrm{m}^{3}$, visibility improved perceptibly at Xinjin Airport. The critical concentration value varied in different places. For example, it was approximately $50 \mu \mathrm{g} / \mathrm{m}^{3}$ in Beijing and Guangzhou [55] and $30 \mu \mathrm{g} / \mathrm{m}^{3}$ in the central area of Liaoning Province [56]. The critical value at Xinjin Airport was comparatively higher. 




(a)

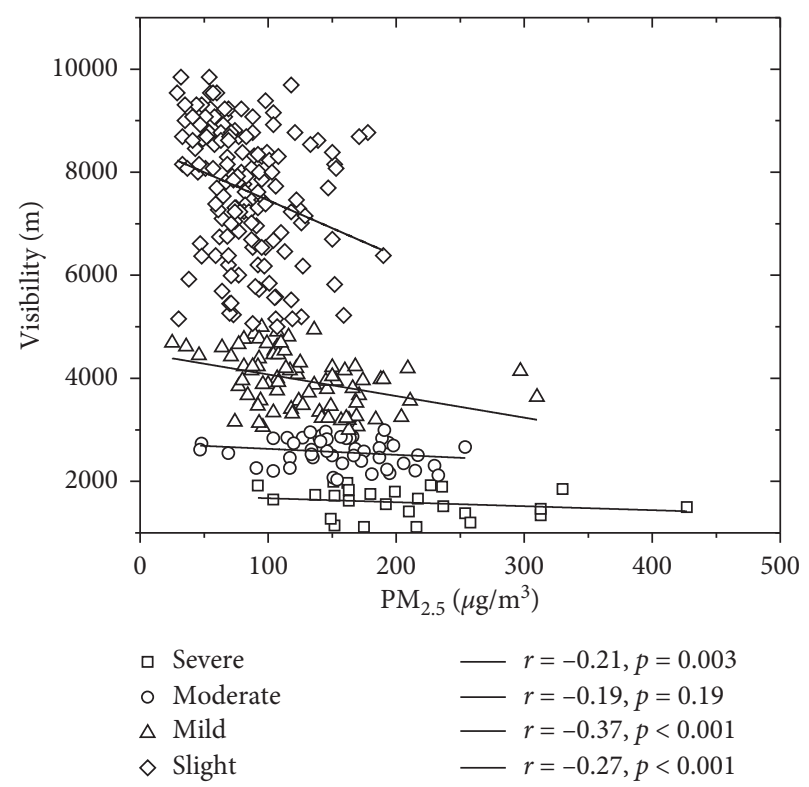

(b)

FIGURE 5: Relation between visibility and relative humidity (a) and $\mathrm{PM}_{2.5}$ concentration (b) under different haze levels.

Table 2 shows that there were significant negative correlations between visibility and $\mathrm{PM}_{2.5}$ concentration under all $\mathrm{RH}$ ranges, with correlation at the $99 \%$ confidence level. The coefficient was highest $(0.755)$ when the $\mathrm{RH}$ range was $70 \% \leqq \mathrm{RH}<80 \%$. When the range was $80 \% \leqq \mathrm{RH}<90 \%$, the value was 0.670 . The correlation coefficients were weaker when the ranges were $\mathrm{RH}<60 \%$ and $60 \% \leqq \mathrm{RH}<70 \%$. There were regional differences in the same range of $\mathrm{RH}$. The correlation was the strongest when the range was $80 \% \leqq$ $\mathrm{RH}<90 \%$ in Wuhan [53], while it was $70 \% \leqq \mathrm{RH}<80 \%$ in Beijing and Guangzhou [55].

\subsubsection{Multivariate Linear and Nonlinear Correlation.} Based on the above correlation analyses, different combinations of the various meteorological and environmental factors were fitted with visibility. The explained variance of the linear fit for visibility and $\mathrm{PM}_{2.5}$ concentration was $44.6 \%$, and that for RH was $42.3 \%$. As shown in Table 3, when $\mathrm{PM}_{2.5}$ concentration and $\mathrm{RH}$ were fitted together with visibility, the explained variance reached $65.9 \%$. Dew point depression and $\mathrm{RH}$ are physical quantities of water vapor saturation and are collinear. When the influence of $\mathrm{PM}_{2.5}$ concentration, $\mathrm{RH}$, and dew point depression on visibility was taken into account, the $P$-value of the $t$-test of dew point depression was 0.457 , which was much higher than the critical value 0.05 . Therefore, dew point depression was eliminated from the multivariate linear fit. Temperature and wind speed were fitted with $\mathrm{PM}_{2.5}$ concentration and $\mathrm{RH}$, and the corresponding explained variances were $66.4 \%$ and $65.5 \%$, respectively. These factors were not collinear, but the $P$-values of the $t$-test of the temperature and wind speed were 0.069 and 0.651 , respectively; both were greater than 0.05. Compared with $\mathrm{PM}_{2.5}$ concentration and $\mathrm{RH}$, the impacts of temperature and wind speed on visibility were not significant and were not considered in the multivariate linear regression equation.

In summary, temperature, wind speed, and air pressure were eliminated due to their low significance, and dew point depression and $\mathrm{RH}$ were not considered simultaneously because of their collinearity. Therefore, $\mathrm{PM}_{2.5}$ concentration and $\mathrm{RH}$ were used in the multiple linear regression equation of winter visibility:

$$
\text { VIS }=16657.056-19.691 \mathrm{PM} 2.5-126.738 \mathrm{RH} .
$$

According to the results of the nonlinear correlation analyses, due to the collinearity between dew point depression and $\mathrm{RH}$, only $\mathrm{PM}_{2.5}$ concentration, $\mathrm{RH}$, and wind speed were used in the multivariate nonlinear regression equation of the visibility:

$$
\mathrm{VIS}=17009.236-1356.814 \mathrm{PM} 2.5^{0.352}-679.557 e 0.026 \mathrm{RH}+1353.76 e^{-6.602 \mathrm{~V}}
$$

The $R^{2}$ value was 0.681 at the $99 \%$ confidence level. The combination of the three factors could explain the change in visibility by $68.1 \%$, which was better than the result of the multivariate linear regression equation.
3.3. Verification of Regression Equation. To verify the effectiveness of the visibility estimation of each factor combination, we used the winter observation data at Xinjin Airport from 2017 to examine the regression 




(a)

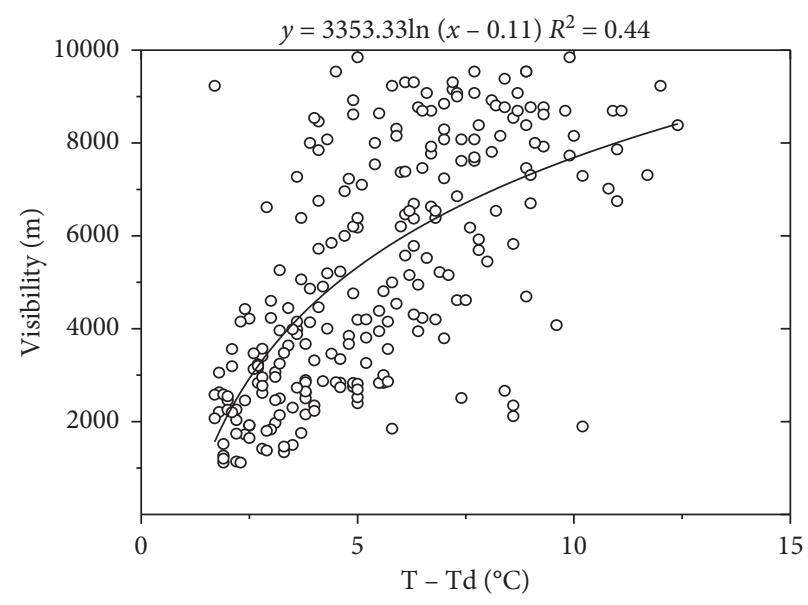

(c)



(b)



(d)

FiguRE 6: Scatter and nonlinear regression curve between visibility and $\mathrm{PM}_{2.5}$ concentration (a), relative humidity (b), dew point depression (c), and wind speed (d).

equations. As seen in Figure 8, the correlation coefficient between the multivariate linear and nonlinear fitting values and the observed visibility was 0.75 and 0.76 , respectively. The variation tendency of the fitting value was the same as the observed value.

Using the refined index of model performance developed by Willmott [57], the statistical index for the multivariate linear model was 0.77 and 0.72 for the nonlinear regression equation. This indicated that both models could simulate the change of invisibility, but visibility simulated by the multivariate linear model was more accurate than that simulated by the nonlinear regression equation. Maybe, due to the fact that various statistical measures were taken into account in the two statistical indices, this result of Willmott's refined index was different from the correlation coefficient, but both of them could reflect the good relationship between observations and predictions.

In the winter of 2017, the average observed value for visibility was $5983.8 \mathrm{~m}$, the fitted values were $5876.6 \mathrm{~m}$ (linear) and $5794.2 \mathrm{~m}$ (nonlinear), and the average deviations were $107.3 \mathrm{~m}$ (linear) and $189.6 \mathrm{~m}$ (nonlinear), respectively. The residual errors in December, January, and February were $-40.9 \mathrm{~m}$ (linear) and $-54.7 \mathrm{~m}$ (nonlinear), $-840.8 \mathrm{~m}$ (linear), and $-547.2 \mathrm{~m}$ (nonlinear), and $1633.1 \mathrm{~m}$ (linear), and $1845.0 \mathrm{~m}$ (nonlinear). The fitting equation produced the best results in December, followed by those in January, and February was the worst. Other factors could have affected the change in visibility in February which was not obvious in other months. Pollutant materials, such as $\mathrm{SO}_{2}$ and $\mathrm{NO}_{2}$, were not considered in this paper. However, studies have shown that routine meteorological parameters are important factors affecting the formation, transportation, and distribution of $\mathrm{SO}_{2}$ and $\mathrm{NO}_{2}[47,48]$. As temperature increases, the concentration of $\mathrm{SO}_{2}$ and $\mathrm{NO}_{2}$ decreases [49], and this can lead to an increase in visibility to a certain extent.

In general, the linear composition of $\mathrm{PM}_{2.5}$ concentration and $\mathrm{RH}$ and the nonlinear composition of $\mathrm{PM}_{2.5}$ concentration, $\mathrm{RH}$, and wind speed can both well estimate the change of winter visibility of 2017 at Xinjin Airport. 


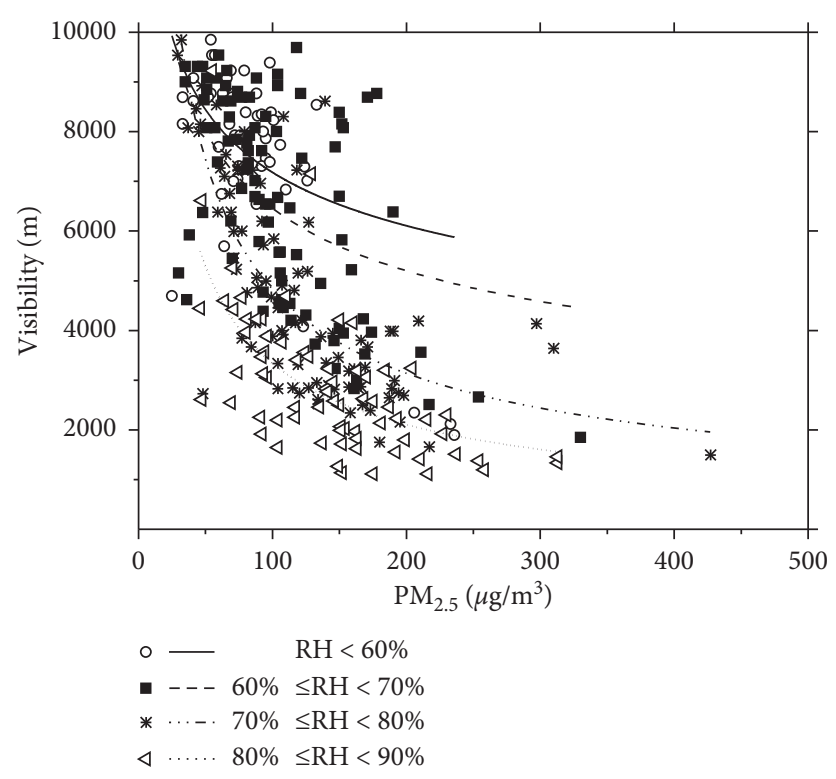

FIGURE 7: Relationship between atmospheric visibility and $\mathrm{PM}_{2.5}$ concentration under different relative humidity conditions.

TABle 2: Quantitative relationships between visibility and $\mathrm{PM}_{2.5}$ concentration under different relative humidity conditions. Note: ${ }^{* *}$ indicates that the significance level of $a=0.01$ has been passed.

\begin{tabular}{lccc}
\hline Relative humidity & Quantitative relationship & $R^{2}$ & Correlation coefficient \\
\hline $\mathrm{RH}<60 \%$ & VIS $=56990 \mathrm{PM}_{2.5}{ }^{-0.472}$ & $0.341^{* *}$ & -0.583 \\
$60 \% \leqq \mathrm{RH}<70 \%$ & VIS $=47354 \mathrm{PM}_{2.5}{ }^{-0.445}$ & $0.333^{* *}$ & -0.574 \\
$70 \% \leqq \mathrm{RH}<80 \%$ & VIS $=102894 \mathrm{PM}_{2.5}^{-0.674}$ & $0.570^{* *}$ & -0.755 \\
$80 \% \leqq \mathrm{RH}<90 \%$ & VIS $=78532 \mathrm{PM}_{2.5}^{-0.698}$ & $0.451^{* *}$ & -0.670 \\
\hline
\end{tabular}

TABLE 3: Regression equations and $R^{2}(\mathrm{r})$ with different types of factors.

\begin{tabular}{lrc}
\hline Factors & Regression equation & $\begin{array}{c}\text { Decisive coefficient (correlation } \\
\text { coefficient) }\end{array}$ \\
\hline $\mathrm{PM}_{2.5}, \mathrm{RH}$ & $\mathrm{VIS}=16657.056-19.691 \mathrm{PM} 2.5-126.738 \mathrm{RH}$ & $0.659(0.812)^{* *}$ \\
$\mathrm{PM}_{2.5}, \mathrm{RH}, \mathrm{T}$ & $\mathrm{VIS}=17752.263-19.051 \mathrm{PM} 2.5-132.442 \mathrm{RH}-76.068 \mathrm{~T}$ & $0.664(0.815)^{* *}$ \\
$\mathrm{PM}_{2.5}, \mathrm{RH}, \mathrm{V}$ & $\mathrm{VIS}=166447.836-19.541 \mathrm{PM} 2.5-125.441 \mathrm{RH}+99.352 \mathrm{~V}$ & $0.655(0.812)^{* *}$ \\
$\mathrm{PM}_{2.5}, \mathrm{RH}, \mathrm{V}, \mathrm{P}, \mathrm{T}$ & $\mathrm{VIS}=-1238.269-18.545 \mathrm{PM} 2.5-130.692 \mathrm{RH}-57.256 \mathrm{~T}+101.246 \mathrm{~V}+16.568 \mathrm{P}$ & $0.665(0.815)^{* *}$ \\
\hline
\end{tabular}

Note. ${ }^{* *}$ The significance level of $a=0.01$ has been passed.

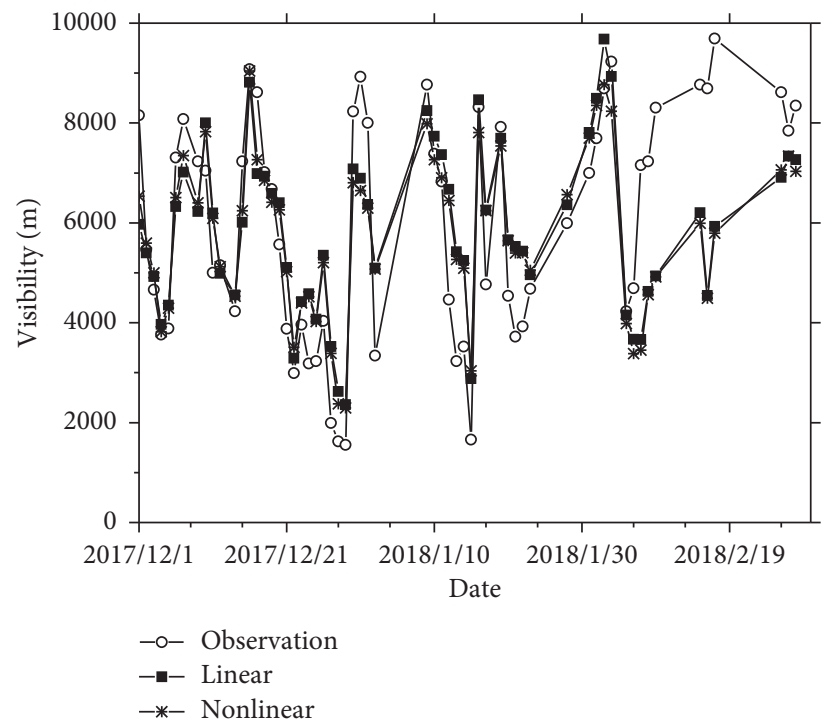

FIgURE 8: Time series of daily observed visibility and simulated visibility by linear and nonlinear regression equations. 


\section{Conclusions and Discussion}

Trends in winter visibility, and the influence of atmospheric aerosol particles and meteorology on visibility, were analyzed between January 1, 2013, and December 31, 2017, using daily mean mass concentrations of $\mathrm{PM}_{2.5}$ from Chengdu, published by the Sichuan Environmental Monitoring Station and daily mean meteorological data (e.g., temperature, $\mathrm{RH}$, wind (wind direction and wind speed), and visibility) from Xinjin Airport. Daily mean meteorological data were calculated by averaging 13 hourly data points (taken from 8:00 am to 8:00 pm) from Xinjin Airport. The hourly meteorological data were collected and processed by automatic observation equipment in the observation station at Xinjin Airport. Visibility was determined by an observer, standing on the observation platform and looking towards surrounding reference features. The observer recorded visibility in all directions, calculated the visibility regarding the MOR value of the forward scatter visibility meter, adjusted within a certain range, and then determined the dominant visibility.

Between 2013 and 2017, the average winter visibility at Xinjin Airport was lowest in January, followed by that in December. The occurrence frequency of haze days in winter was much higher than that of nonhaze (clean) days, being $90.2 \%$ and $9.8 \%$, respectively. These haze days were mainly mild haze days, with an occurrence frequency of $44.4 \%$, while severe haze days were the least frequent, occurring on $7.7 \%$ of all haze days. Exacerbated by pollution, average $\mathrm{RH}$ increased from $64.9 \%$ for slight haze to $82.1 \%$ for heavy haze, and the corresponding $\mathrm{PM}_{2.5}$ concentration increased significantly from $83.1 \mu \mathrm{g} / \mathrm{m}^{3}$ to $208 \mu \mathrm{g} / \mathrm{m}^{3}$. The average $\mathrm{PM}_{2.5}$ concentrations for nonhaze days, slight haze days, and mild haze days at Xinjin Airport were relatively similar to those in Wuhan, whereas average concentrations for moderate and severe haze days were $20 \mu \mathrm{g} / \mathrm{m}^{3}$ and $50 \mu \mathrm{g} / \mathrm{m}^{3}$ higher at Xinjin Airport, respectively, which performed a geographical difference [53].

In this study, comprehensive analysis of meteorological and atmospheric factors using correlation analyses showed that between 2013 and 2016, the linear correlation between $\mathrm{PM}_{2.5}$ concentration and visibility was the most evident, followed by that of RH, just like in Guangzhou, $\mathrm{PM}_{2.5}$ had a greater influence on visibility than RH [55]. Visibility had a greater nonlinear correlation with $\mathrm{PM}_{2.5}$ concentration, $\mathrm{RH}$, and dew point depression. When $\mathrm{RH}$ was between $70 \%$ and $80 \%$, the negative correlation between visibility and $\mathrm{PM}_{2.5}$ concentration was the most significant, with the same range as in Beijing and Guangzhou [55], and when it is $80 \% \leqq$ $\mathrm{RH}<90 \%$ in Wuhan [53], the correlation could be described by a power function.

Based on the correlation analyses, different combinations of meteorological parameters and atmospheric pollutants were fitted with visibility. The multivariate linear regression equation of $\mathrm{PM}_{2.5}$ concentration and $\mathrm{RH}$ could account for $65.9 \%$ of the variation in winter visibility, and the multivariate nonlinear regression equation of $\mathrm{PM}_{2.5}$ concentration, $\mathrm{RH}$, and wind speed could account for $68.1 \%$ of the variation in winter visibility. Both equations reasonably represented the variation in winter visibility in 2017 .
Other factors could affect the change in visibility, such as cold fronts. Kang et al. [58] indicated that cold fronts were potential carriers of atmospheric pollutants and could transport large amounts of polluted air from upstream to downstream regions, causing a deterioration in air quality and visibility. The distinct basin terrain and regional-scale stationary atmosphere during winter were important factors contributing to the accumulation of $\mathrm{PM}_{2.5}$ in Chengdu, which resulted in continuous heavy pollution weather $[59,60]$.

\section{Data Availability}

In this study, the hourly routine meteorological data were collected from the Xinjin Airport automatic observation station; the air quality data was derived from the multisite regional average data released by the Sichuan Environmental Monitoring Station. All data sets are available by contacting the first author.

\section{Conflicts of Interest}

The authors declare no conflicts of interest.

\section{Authors' Contributions}

Jing Zhang and Pengguo Zhao contributed equally to this work.

\section{Acknowledgments}

Pengguo Zhao acknowledges the China Scholarship Council for support (201808515075). This research was funded by the National Natural Science Foundation of China (41905126 and 41875169), the Sichuan Science and Technology Project (2018SZ0316 and 2019JDKP0046), the Chengdu Science and Technology Anti-Haze Project (2018-ZM01-00038-SN), the Chengdu Science and Technology Benefit Project (2016MH01-00038-SF), the National Key R\&D Program of China (2018YFC1506104), and the Application and Basic Research of Sichuan Department of Science and Technology (2019YJ0316).

\section{References}

[1] D. Founda, S. Kazadzis, N. Mihalopoulos, E. Gerasopoulos, M. Lianou, and P. I. Raptis, "Long-term visibility variation in Athens (1931-2013): a proxy for local and regional atmospheric aerosol loads," Atmospheric Chemistry and Physics, vol. 16, no. 17, pp. 11219-11236, 2016.

[2] C. A. Pope, R. T. Burnett, M. J. Thun et al., "Lung cancer, cardiopulmonary mortality, and long-term exposure to fine particulate air pollution," JAMA, vol. 287, no. 9, pp. 1132-1141, 2002.

[3] J. M. Samet, F. Dominici, F. C. Curriero, I. Coursac, and S. L. Zeger, "Fine particulate air pollution and mortality in 20 U.S. Cities, 1987-1994," New England Journal of Medicine, vol. 343, no. 24, pp. 1742-1749, 2000.

[4] H. Hauck, A. Berner, T. Frischer et al., "AUPHEP-Austrian Project on health effects of particulates-general overview," 
Atmospheric Environment, vol. 38, no. 24, pp. 3905-3915, 2004.

[5] M. Doyle and S. Dorling, "Visibility trends in the UK 1950-," Atmospheric Environment, vol. 36, no. 19, pp. 3161-3172, 2002.

[6] N. M. Mahowald, J. A. Ballantine, J. Feddema, and N. Ramankutty, "Global trends in visibility: implications for dust sources," Atmospheric Chemistry and Physics, vol. 7, no. 12, pp. 3309-3339, 2007.

[7] A. Molnar, E. Meszaros, K. Imre, and A. Rull, "Trends in visibility over Hungary between 1996 and 2002," Atmospheric Environment, vol. 42, no. 11, pp. 2621-2629, 2008.

[8] Y. I. Tsai, S.-C. Kuo, W.-J. Lee, C.-L. Chen, and P.-T. Chen, "Long-term visibility trends in one highly urbanized, one highly industrialized, and two rural areas of Taiwan," Science of the Total Environment, vol. 382, no. 2-3, pp. 324-341, 2007.

[9] J.-Y. Lee, W.-K. Jo, and H.-H. Chun, "Long-term trends in visibility and its relationship with mortality, air-quality index, and meteorological factors in selected areas of korea," Aerosol and Air Quality Research, vol. 15, no. 2, p. 673, 2015.

[10] K. Wang, R. E. Dickinson, and S. Liang, "Clear sky visibility has decreased over land globally from 1973 to 2007," Science, vol. 323, no. 5920, pp. 1468-1470, 2009.

[11] Y. Hu, L. Yao, Z. Cheng, and Y. Wang, "Long-term atmospheric visibility trends in megacities of China, India and the United States," Environmental Research, vol. 159, pp. 466-473, 2017.

[12] A. Singh, W. R. Avis, and F. D. Pope, "Visibility as a proxy for air quality in East Africa," Environmental Research Letters, vol. 15 , no. 8, p. $84002,2020$.

[13] A. K. Jaswal, N. Kumar, A. K. Prasad, and M. Kafatos, "Decline in horizontal surface visibility over India (1961-2008) and its association with meteorological variables," Natural Hazards, vol. 68, no. 2, pp. 929-954, 2013.

[14] D. Bäumer, B. Vogel, S. Versick, R. Rinke, O. Möhler, and M. Schnaiter, "Relationship of visibility, aerosol optical thickness and aerosol size distribution in an ageing air mass over South-West Germany," Atmospheric Environment, vol. 42, no. 5, pp. 989-998, 2008.

[15] A. Singh, W. J. Bloss, and F. D. Pope, "60 years of UK visibility measurements: impact of meteorology and atmospheric pollutants on visibility," Atmospheric Chemistry and Physics, vol. 17, no. 3, pp. 2085-2101, 2017.

[16] H. Horvath, "Estimation of the average visibility in central Europe," Atmospheric Environment, vol. 29, no. 2, pp. 241-246, 1995.

[17] J. Deng, K. Du, K. Wang, C.-S. Yuan, and J. Zhao, "Long-term atmospheric visibility trend in Southeast China, 1973-2010," Atmospheric Environment, vol. 59, pp. 11-21, 2012.

[18] D. Xue, C. Li, and Q. Liu, "Visibility characteristics and the impacts of air pollutants and meteorological conditions over Shanghai, China," Environmental Monitoring and Assessment, vol. 187, pp. 363-372, 2015.

[19] J. Zhou, R. Zhang, J. Cao, J. C. Chow, and J. G. Watson, "Carbonaceous and ionic components of atmospheric fine particles in Beijing and their impact on atmospheric visibility," Aerosol and Air Quality Research, vol. 12, no. 4, pp. 492-502, 2012.

[20] M. Lin, J. Tao, C.-Y. Chan et al., "Regression analyses between recent air quality and visibility changes in megacities at four haze regions in China," Aerosol and Air Quality Research, vol. 12, no. 6, pp. 1049-1061, 2012.
[21] D. Chang, Y. Song, and B. Liu, "Visibility trends in six megacities in China 1973-2007," Atmospheric Research, vol. 94, no. 2, pp. 161-167, 2009.

[22] H. Che, X. Zhang, Y. Li, Z. Zhou, and J. J. Qu, "Horizontal visibility trends in China 1981-2005," Geophysical Research Letters, vol. 34, no. 24, 2007.

[23] X. Deng, X. Tie, D. Wu et al., "Long-term trend of visibility and its characterizations in the Pearl River Delta (PRD) region, China," Atmospheric Environment, vol. 42, no. 7, pp. 1424-1435, 2008.

[24] Y. Zhou, B. Zhu, and Z. Han, "Analysis of visibility characteristics and connecting factors over the Yangtze River Delta Region during winter time," China Environmental Science, vol. 36, no. 3, pp. 660-669, 2016.

[25] Z. Zhang, B. Wang, and X. Deng, "Impact of PM-1 concentration on visibility and the aerosol hygroscopic growth factor in Guangzhou," Journal of University of Chinese Academy of Science, vol. 31, no. 3, pp. 397-402, 2014.

[26] P. Zhao, X. Zhang, X. Xu, and X. Zhao, "Long-term visibility trends and characteristics in the region of Beijing, Tianjin, and Hebei, China," Atmospheric Research, vol. 101, no. 3, pp. 711-718, 2011.

[27] Q. H. Zhang, J. P. Zhang, and H. W. Xue, "The challenge of improving visibility in Beijing," Atmospheric Chemistry and Physics, vol. 10, no. 16, pp. 7821-7827, 2010.

[28] W. Fu, Z. Chen, Z. Zhu et al., "Long-term atmospheric visibility trends and characteristics of 31 provincial capital cities in China during 1957-2016," Atmosphere, vol. 9, no. 8, pp. 318-334, 2018.

[29] S. Xiao, Q. Y. Wang, J. J. Cao et al., "Long-term trends in visibility and impacts of aerosol composition on visibility impairment in Baoji, China," Atmospheric Research, vol. 149, pp. 88-95, 2014.

[30] Y. Chen and S.-d. Xie, "Long-term trends and characteristics of visibility in two megacities in southwest China: Chengdu and Chongqing," Journal of the Air \& Waste Management Association, vol. 63, no. 9, pp. 1058-1069, 2013.

[31] J. C. Chow, J. D. Bachmann, S. S. G. Wierman et al., "Visibility: science and regulation," Journal of the Air \& Waste Management Association, vol. 52, no. 9, pp. 973-999, 2002.

[32] J. Qiu and L. Yang, "Variation characteristics of atmospheric aerosol optical depths and visibility in North China during 1980-1994," Atmosphere Environment, vol. 34, pp. 603-609, 2000.

[33] R. J. Park, D. J. Jacob, and M. Chin, "Sources of carbonaceous aerosols over the United States and implications for natural visibility," Journal of Geophysical Research, vol. 108, pp. 4355-4373, 2003.

[34] R. J. Park, D. J. Jacob, and N. Kumar, "Regional visibility statistics in the United States: natural and transboundary pollution influences, and implications for the Regional Haze Rule," Atmosphere Environment, vol. 40, pp. 405-5423, 2006.

[35] S. Tiwari, S. Payra, M. Mohan, S. Verma, and D. S. Bisht, "Visibility degradation during foggy period due to anthropogenic urban aerosol at Delhi, India," Atmospheric Pollution Research, vol. 2, no. 1, pp. 116-120, 2011.

[36] D. Wu, X. Tie, C. Li et al., "An extremely low visibility event over the Guangzhou region: a case study," Atmospheric Environment, vol. 39, no. 35, pp. 6568-6577, 2005.

[37] L.-x. Yang, D.-c. Wang, S.-h. Cheng et al., "Influence of meteorological conditions and particulate matter on visual range impairment in Jinan, China," Science of the Total Environment, vol. 383, no. 1-3, pp. 164-173, 2007. 
[38] J.-J. Cao, Q.-Y. Wang, J. C. Chow et al., "Impacts of aerosol compositions on visibility impairment in Xi'an, China," Atmospheric Environment, vol. 59, pp. 559-566, 2012.

[39] W. Rogula-Kozlowska, K. Lejnowski, and P. Rogula-Kopiec, "“Spatial and seasonal variability of the mass concentration and chemical composition of $\mathrm{PM}_{2.5}$ in Poland," Air Quality," Atmosphere Health, vol. 7, pp. 41-58, 2014.

[40] Q. Wang, J. Cao, and J. Tao, "Long-term trends in visibility and at Chengdu, China," Plos One, vol. 7, no. 8, p. e68894, 2013.

[41] J. H. Seinfeld and S. N. Pandis, Atmospheric Chemistry and Physics from Air Pollution to Climate Change, 2nd edition, 2006.

[42] Y. I. Tsai, "Atmospheric visibility trends in an urban area in Taiwan 1961-2003," Atmospheric Environment, vol. 39, no. 30, pp. 5555-5567, 2005.

[43] C.-C. Wen and H.-H. Yeh, "Comparative influences of airborne pollutants and meteorological parameters on atmospheric visibility and turbidity," Atmospheric Research, vol. 96, no. 4, pp. 496-509, 2010.

[44] K. Du, C. Mu, J. Deng, and F. Yuan, "Study on atmospheric visibility variations and the impacts of meteorological parameters using high temporal resolution data: an application of Environmental Internet of Things in China," International Journal of Sustainable Development \& World Ecology, vol. 20, no. 3, pp. 238-247, 2013.

[45] G. Majewski, P. O. Czechowski, and A. J. Badyda, "Effect of air pollution on visibility in urban conditions," Warsaw Case Study," Environmental Protection Engineering, vol. 40, no. 2, pp. 47-64, 2014.

[46] X. Liu, Y. Zhang, Y. Cheng, M. Hu, and T. Han, "Aerosol hygroscopicity and its impact on atmospheric visibility and radiative forcing in Guangzhou during the 2006 PRIDE-PRD campaign," Atmospheric Environment, vol. 60, pp. 59-67, 2012.

[47] Q. Jiang, Y. L. Sun, Z. Wang, and Y. Yin, "Aerosol composition and sources during the Chinese spring festival: fireworks, secondary aerosol, and holiday effects," Atmospheric Chemistry and Physics, vol. 15, no. 11, pp. 6023-6034, 2015.

[48] J. Feng, H. Yu, X. Su et al., "Chemical composition and source apportionment of PM2.5 during Chinese Spring Festival at Xinxiang, a heavily polluted city in North China: fireworks and health risks," Atmospheric Research, vol. 182, pp. 176-188, 2016.

[49] H. Ten Brink, B. Henzing, R. Otjes, and E. Weijers, "Visibility in The Netherlands during new year's fireworks: the role of soot and salty aerosol products," Atmospheric Environment, vol. 173, pp. 289-294, 2018.

[50] Y. Wang, Q. Ying, J. Hu, and H. Zhang, "Spatial and temporal variations of six criteria air pollutants in 31 provincial capital cities in China during 2013-2014," Environment International, vol. 73, pp. 413-422, 2014.

[51] P. Zhao, G. T. Tuygun, B. Li et al., "The effect of environmental regulations on air quality: a long-term trend analysis of $\mathrm{SO}_{2}$ and $\mathrm{NO}_{2}$ in the largest urban agglomeration in southwest China," Atmospheric Pollution Research, vol. 10, no. 6, pp. 2030-2039, 2019.

[52] CMA. QX/T 113-2010, Observation and Forecasting Levels of Haze, China Meteorological Press, Beijing, China, 2010.

[53] Y. Bai, H. Qi, and L. Liu, "Study on the nonlinear relationship among the visibility, $\mathrm{PM}_{2.5}$ concentration and relative humidity in Wuhan and the visibility prediction," Acta Meteorologica Sinica, vol. 7, no. 2, pp. 189-199, 2016.
[54] J. Deng, T. Wang, and Z. Jiang, "Characterization of visibility and its affecting factors over Nanjing, China," Atmosphere Research, vol. 4, pp. 16-29, 2011.

[55] Y. Chen, D. Zhao, F. Chai, and M. Zhang, "Correlation between the atmospheric visibility and aerosol fine particle concentrations in Guangzhou and Beijing," China Environmental Science, vol. 30, no. 7, pp. 967-971, 2010.

[56] N. Liu, Y. Ma, and Y. Wang, "Observational study of atmospheric visibility in summer in the area of multi-cities on central Liaoning Province," Acta Meteorologica Sinica, vol. 70, no. 4, pp. 814-820, 2012.

[57] C. J. Willmott, S. M. Robeson, and K. Matsuura, "A refined index of model performance," International Journal of Climatology, vol. 32, no. 13, pp. 2088-2094, 2012.

[58] H. Kang, B. Zhu, J. Gao et al., "Potential impacts of cold frontal passage on air quality over the Yangtze river delta, China," Atmospheric Chemistry and Physics, vol. 19, no. 6, pp. 3673-3685, 2019.

[59] Y. Chen and S. Xie, "Temporal and spatial visibility trends in the Sichuan Basin, China, 1973 to 2010," Atmospheric Research, vol. 112, pp. 25-34, 2012.

[60] J. Tao, L. Zhang, J. Cao et al., "Characterization and source apportionment of aerosol light extinction in Chengdu, southwest China," Atmospheric Environment, vol. 95, no. 1, pp. 552-562, 2014. 